\title{
Future Precipitation Scenarios over Italy
}

\author{
Paola Faggian
}

check for updates

Citation: Faggian, P. Future Precipitation Scenarios over Italy. Water 2021, 13, 1335. https: / / doi.org/10.3390/w13101335

Academic Editor: Alberto Bianchi

Received: 10 February 2021

Accepted: 6 May 2021

Published: 11 May 2021

Publisher's Note: MDPI stays neutral with regard to jurisdictional claims in published maps and institutional affiliations.

Copyright: (C) 2021 by the author. Licensee MDPI, Basel, Switzerland. This article is an open access article distributed under the terms and conditions of the Creative Commons Attribution (CC BY) license (https:// creativecommons.org/licenses/by/ $4.0 /)$.
Ricerca sul Sistema Energetico-RSE S.p.A. Via Rubattino, 54, 20134 Milano, Italy; paola.faggian@rse-web.it
Abstract: To support the development of national adaptation policies and measures addressing climate change impacts over Italy, this work aims to analyze projected changes in mean temperatures and precipitations, and extreme events such as droughts and floods, highlighting some local trends in the different Italian regions that have been little considered to date. The investigations are made on the basis of a set of high-resolution Euro-CORDEX models (horizontal resolution $0.11^{\circ}$, about $12 \mathrm{~km}$ ) to infer quantitative assessments about the danger of climate changes under three different Representative Concentration Pathways (RCPs): business as usual scenario, i.e., without a reduction in green-house gas emissions (RCP 8.5), medium stabilization scenario (RCP 4.5) and mitigation scenario (RCP 2.6). After filtering the models with limited performances in reconstructing the current climate, the multi-model climate change scenarios were characterized by comparing the ensemble mean values computed for the base-line period (1971-2000) with those elaborated for the short- (2021-2050), medium- (2041-2070) and long-term (2071-2100). Two WMO ETCCDI indices were considered to investigate climate extremes: Consecutive Dry Days and extreme precipitations. Despite some uncertainties (related to discrepancies among the models), drought conditions and extreme precipitations will likely exacerbate in the coming decades without mitigation (RCP 8.5). Such conditions will be less critical if partial mitigation actions will be undertaken (RCP 4.5) and are expected to be significantly reduced with decarbonization policies (RCP 2.6).

Keywords: Euro-CORDEX models; climate extremes; future projections

\section{Introduction}

Climate changes are currently affecting every country, destroying the basic elements of life for people and natural ecosystems around the world. Data from the Munich Reinsurance Company suggest an increase in meteorological and climatic catastrophic events (such as floods and droughts) since the mid-1980s and advise that climate-related hazards are at historically high levels at present [1].

The Sustainable Development Goals (SDGs) adopted by the United Nations in September 2015 state the need to take urgent action to fight climate change and its impacts [2], with the SDG 13 dealing only with "Climate Action" [3].

Because fresh water plays a central role in the functioning of the biosphere and supporting life, one of the greatest concerns is the response of the Earth's hydrologic cycle to global warming, as hundreds of millions of people could suffer from water shortages and coastal flooding as the world warms. Indeed, the natural cycle of water availability is now under threat, a situation known as 'water vulnerability' [4]. The first major driver of alterations in the hydrological system is land-use changes caused, for example, by the growth in urban areas. Water withdrawal is another cause of water vulnerability, especially in the agricultural sector: agriculture accounts for $33 \%$ of total water use in Europe and reaches up to $80 \%$ in parts of Southern Europe [4]. The third main cause of water vulnerability is climate change, even if its effects are difficult to discern given the natural variability in the hydrological cycle. There is growing evidence that the recent increase in floods and droughts in the world may be related to anthropogenic influences: some indications of the increase in precipitation extremes observed over different regions of the world have been highlighted in different IPCC reports $[5,6]$ and other studies, such 
as [7]. Moreover, both models and observations point out that precipitation extremes increase with higher temperatures [8]. Model projections indicate that the characteristics of precipitation are going to be substantially modified by global warming, most likely to a greater extent than mean precipitation itself [9].

Globally, there has been an increase of about $1.1^{\circ} \mathrm{C}$ since pre-industrial period (18501900) [10]. The latest five-year average global temperature is the highest ever recorded. Across Europe, there has been an increase of almost $2.0^{\circ} \mathrm{C}$ since the latter half of the 19th century [11].

All critical infrastructures (i.e., the array of physical assets, functions, and systems vital to ensuring human health, wealth, and security) may be seriously damaged by climate changes. Focusing on Europe, damage from climate hazard impacts to critical infrastructures could increase 10-fold by the end of the century [12].

As mentioned by the U.S. Department of Energy [13], renewable energy sources clearly depend on weather conditions. Notably, droughts could seriously impact hydropower. This may generate very critical conditions as hydropower remains the predominant lowcost and reliable source of energy at global level and stabilizes the provision of electricity while leaving room for investments in alternate clean-energy technologies. In case of water shortage, conventional power generation will be affected too. Thermoelectric power generation facilities are at risk if water availability decreases and/or ambient air and water temperatures increase. These meteorological conditions reduce the efficiency of cooling and increase the likelihood of exceeding water thermal limits imposed at the intake and, most of all, at the effluent, to protect local ecology. Consequently, such conditions increase the risk of partial or full shutdowns of generation facilities. In addition, droughts and heat waves may cause the failure of underground cable joints of the power network. A reduced temperature range between day and night, and low humidity (typical conditions of drought periods), prevent the heat dissipation of the underground cables, increasing the risk of failure in these conductors, especially in urban areas [14,15].

Additionally, in Italy, the Energy/Electric System infrastructures could be affected by the relevant impacts [16-18]. The publication of the National Energy Strategy [19] established clear goals for the energy sector: reduce energy costs, meet environmental targets, strengthen security of energy supply, and pursue sustainable economic growth. More recently, with the Piano Nazionale Integrato per l'Energia e il Clima 2030 (PNIEC) [20], the national targets for 2030 on energy efficiency, renewable sources and $\mathrm{CO}_{2}$ emission reductions were established. Indeed, Italy has experienced a notable growth in the renewable energy sector by integrating large volumes of variable renewable generation.

Considering that critical infrastructures are designed for a very long lifetime, this study aims to update climate change projections focused on the rainfall regime in Italy, to provide a useful tool to cope with the climate impacts and strengthen resilience and the adaptive capacity of the socio, economic and environmental sectors.

Climate science has improved, and our understanding of the climate system is considerably increased in comparison with previous decades [21]. In recent years, updated future projections have been elaborate, thanks to the results provided by regional climate model simulations from the COordinated Regional climate Downscaling EXperiment (CORDEX) [22,23], which downscales CMIP5 GCM data. A lot of work has been carried out specifically for Europe (among others [24,25]), even if the exact changes and impacts are uncertain and difficult to isolate. In general, there is no water shortage in Europe, but water is unevenly distributed both over time and in space, with large areas experiencing increasing levels of water scarcity and drought [26], and others proving vulnerable to floods. Climate change is predicted to exacerbate the frequency and severity of both droughts and floods in Europe in the coming decades [6], with increasingly serious detrimental socio-economic impacts.

Some significant signals regarding precipitation changes over Italy have been pointed out by Brunetti et al. [27], who found an increase in the precipitation intensity and extreme 
events in the last decades of the century, despite a reduction in the number of wet days, and a decrease in annual precipitation.

Focusing on Italy, Buccignani et al. [28] performed two simulations at a spatial resolution of $0.0715^{\circ}$, driven by the global model CMCC-CM, over the period 1971-2100, by employing the Representative Concentration Pathways RCP 4.5 and RCP 8.5. They found a significant warming expected in Italy at the end of the 21st century, and a general reduction in precipitation, particularly in spring and summer.

In this study, some multi-model scenarios have been elaborated on the basis of several Euro-CORDEX simulations [29] at a $0.11^{\circ}$ spatial resolution under three hypotheses of radiative forcing ( $\mathrm{RCP} 2.6, \mathrm{RCP} 4.5$ and $\mathrm{RCP} 8.5$ ), in order to obtain some new measures about the uncertainties of the future projections.

As it is more interesting to analyze changes in the rainfall regime than the mean precipitation variation to investigate how precipitation change patterns affect different socioeconomic sectors [9], two WMO ETCCDI indices [30], specifically designed to describe climate extremes, have been computed to investigate the drought conditions and extreme precipitations expected over Italy in coming decades.

The study is presented as follows: the datasets and the adopted methodology are presented in Section 2; the results are drawn in Section 3; discussions and conclusions are reported in Section 4.

\section{Datasets and Analysis Method}

The whole Italian territory was included in the analysis domain (Figure 1).

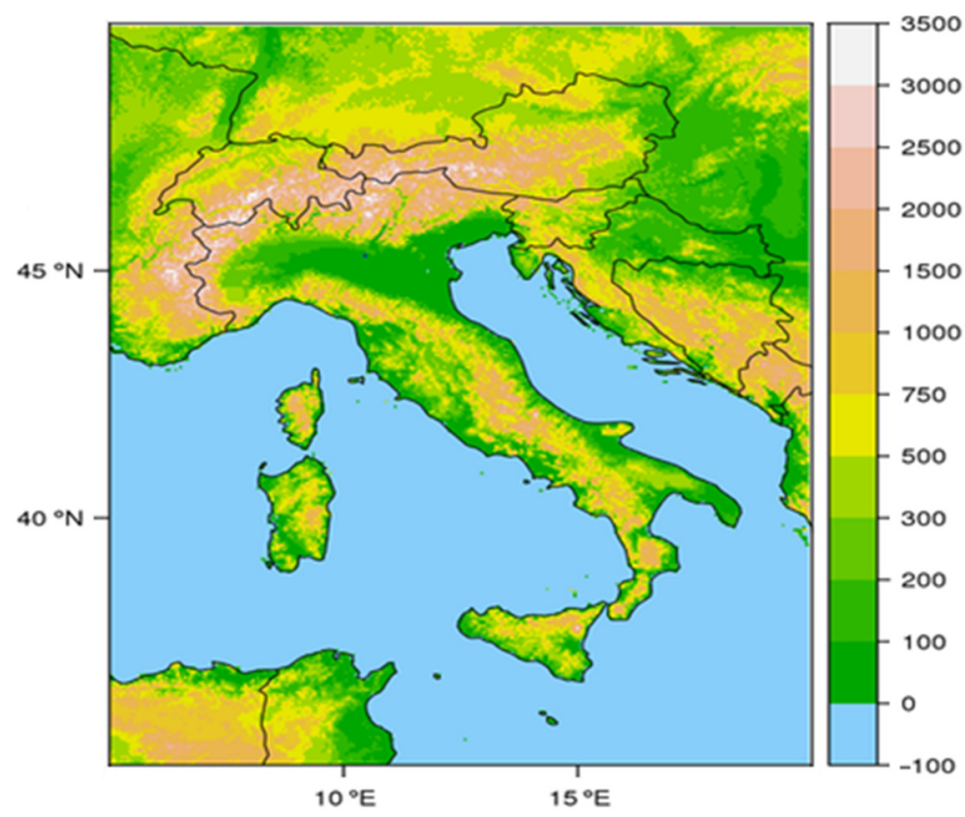

Figure 1. Analysis domain with orography description.

A set of 14 high-resolution Euro-CORDEX models (daily meteorological data at a horizontal resolution of $0.11^{\circ}$, about $12 \mathrm{~km}$, ref [31] was considered (Table 1) to elaborate climate change scenarios from 1971 to 2100. 
Table 1. List of Euro-CORDEX simulations considered in this study. The names of simulations identify the research institute, the global circulation model, and the regional climate model.

\begin{tabular}{ccccc}
\hline Id & Climate Model Simulation & Institute & GCM & RCM \\
\hline 1 & IPSL_CM5A-MR_WRF331F' & IPSL & CM5A-MR & INERIS-WRF331F \\
2 & KNMI_EC-EARTH_RACMO & KNMI & EC-EARTH & RACMO22E \\
3 & CLMcom_EC-EARTH_CCLM & CLMcom & EC-EARTH & CCLM4-8-17 \\
4 & CLMcom_MPI-ESM-LR_CCLM & CLMcom & MPI-M-MPI-ESM-LR & CCLM4-8-17 \\
5 & CLMcom_CNRM-CM5_CCLM & CLMcom & CNRM-CM5 & CCLM4-8-17 \\
6 & DMI_EC-EARTH_HIRHAM & DMI & EC-EARTH & HIRHAM5 \\
7 & KNMI_HADGEM2-ES_RACMO & KNMI & MOHC-HadGEM2-ES & RACMO22E \\
8 & CLMcom_HADGEM2-ES_CCLM & CLMcom & MOHC-HadGEM2-ES & CCLM4-8-17 \\
9 & SMHI_CM5A-MR_RCA & SMHI & CM5A-MR & RCA4 \\
10 & SMHI_CNRM-CM5_RCA & SMHI & CNRM-CM5 & RCA4 \\
11 & SMHI_MPI-ESM-LR_RCA & SMHI & MPI-M-MPI-ESM-LR & RCA4 \\
12 & SMHI_EC-EARTH_RCA & SMHI & EC-EARTH & RCA4 \\
13 & SMHI_HADGEM2-ES_RCA & SMHI & MOHC-HadGEM2-ES & RCA4 \\
14 & CNRM_CNRM_CM5_ALADIN53 & CNRM & CNRM-CM5 & ALADIN53 \\
\hline
\end{tabular}

Because of the uncertainty regarding future anthropogenic emissions, as well as future land-use changes, future climate projections were elaborated using model simulations realized under three different hypothesis of radiative forcing; each provides a plausible description of how the future may evolve with respect to a number of variables, including socio-economic change, technological change, energy and land use, greenhouse gas emissions and air pollutants [32]: RCP 8.5 should be seen as very high baseline emission scenario (business-as-usual scenario), RCP 4.5 can be interpreted as an intermediate mitigation scenario, while RCP 2.6 is representative of a mitigation scenario leading to a very low forcing level.

In addition, the observational dataset E-OBS [33] was used as reference to characterize the current climate. E-OBS [34] provides gridded daily data at a spatial resolution of $0.25 \times 0.25$ degrees from 1961 over Europe. The delivered variables are mean, minimum, and maximum temperature, and total precipitation.

Following the recommendations stated in the Program for Climate Model Diagnosis and Intercomparison $[35,36]$ the multi-model ensemble mean approach was adopted to elaborate future climate scenarios, in order to improve the accuracy and reliability of probabilistic projections compared to single-model realizations.

Moreover, the Wilcoxon rank-sum test (a non-parametric test) was used to identify the areas that will likely be affected by significant climate change (at 95\%).

First of all, the models' performances in reconstructing the current climate (1971-2000) were checked [37]. For this purpose, a MESAN reanalysis dataset [38] was used in addition to E-OBS. Mod 1 and Mod 14, using, respectively, the regional models WRF331F and ALADIN53 (Table 1), showed some shortcomings in representing the observed climate conditions, especially in reproducing intra-annual variability in precipitations (Figure 2). Therefore, they were discarded in the elaboration of future multi-model mean (MMM) scenarios.

The effects of climate changes over Italy were studied by comparing the reference climate period $(\mathrm{REF}=1971-2000)$ with the future scenarios in the short (FUT1 = 2021-2050), medium (FUT2 = 2041-2070) and long (FUT3 = 2071-2100) term.

Dry spell length and heavy precipitation intensity are affected by various characteristics of the climatic system, most notably precipitation (intensity, duration, amount, timing, phase-rain or snow). However, temperature patterns are also responsible for such phenomena. Therefore, gradual changes in surface temperature and total precipitation (pr) were considered. Changes in extreme events were analyzed using two WMO ETCCDI indices: Consecutive Dry Days (CDD) to investigate drought conditions, and R99PTOT to characterize extreme precipitation. 


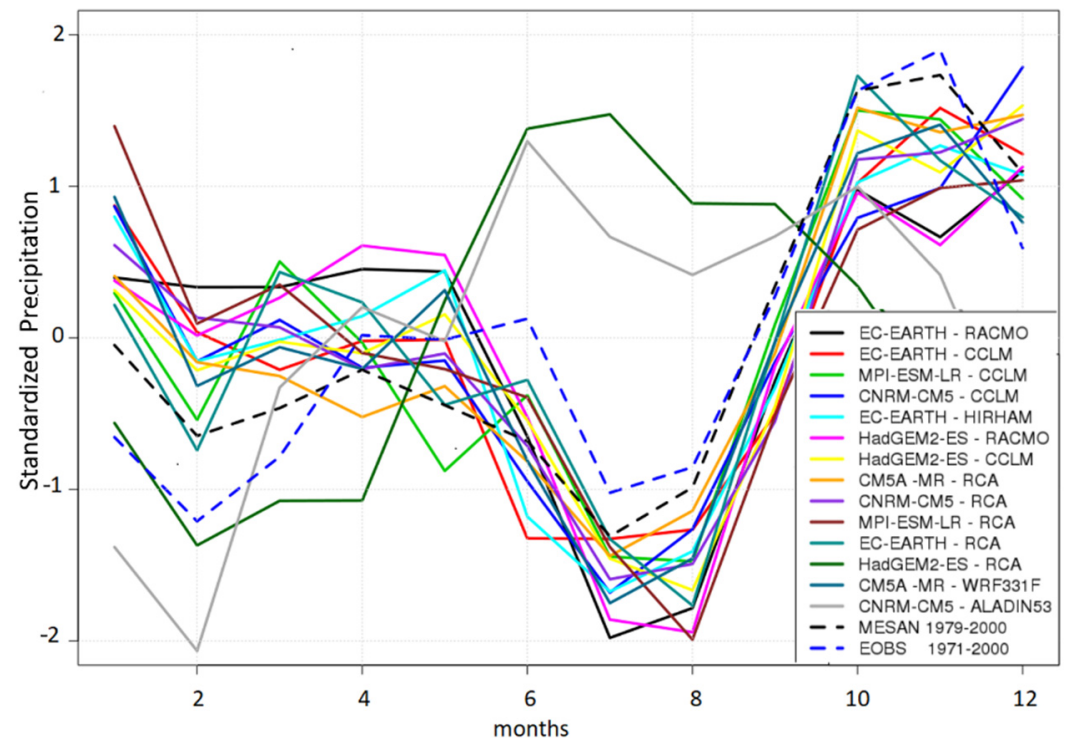

Figure 2. Seasonal cycle of precipitation according to the 14 Euro-CORDEX simulations (colored lines) in comparison with E-OBS and MESAN data (blue and black dashed lines, respectively), calculated for the period 1971-2000 (MESAN data refer to the 1979-2000 years) [31].

\section{Results}

Climate change scenarios are presented in terms of seasonal anomalies, i.e., by considering the differences between the climate future values and the reference ones in the four seasons: winter (DJF), spring (MAM), summer (JJA) and autumn (SON).

Such variations are described by means of some figures, each composed of 12 panels (four columns by three rows) to characterize the expected changes for each season-in the order DJF, MAM, JJA and SON from the first to the fourth column-and for each emission scenario-RCP 2.6, RCP 4.5 and RCP 8.5, from the the first to the third row. Moreover, the grid cells of each panels are stippled if they are characterized by a significant change according to the Wilcoxon rank-sum test applied to compare the two related samples and determine whether they have the same distribution.

\subsection{Gradual Changes of Climate}

The seasonal mean temperature anomalies at the short-, medium-, and long-term with respect to the baseline period 1971-2000 are described, respectively, by Figures 3-5. In these figures, each grid point is stippled. This means that a significant temperature increase is expected everywhere, according to Wilcoxon rank-sum test.

Some differences in the temperature anomalies are clearly visible in the coming decades (Figure 3): according to the RCP 2.6 configuration, the temperature increase will be limited within $1^{\circ} \mathrm{C}$ (first row of Figure 3); in case of partial mitigation actions (RPC 4.5), the warming is projected to be less than 1 degree on average, and between 1.5 and $2{ }^{\circ} \mathrm{C}$ in summer (second row of Figure 3); without mitigation (RCP 8.5), temperature is expected to increase between 1.5 and $2{ }^{\circ} \mathrm{C}$ in autumn and winter over the Alps (third row).

In the middle of the century (Figure 4 ), warming is likely to increase, without exceeding $2{ }^{\circ} \mathrm{C}$, under the RCP 2.6 hypothesis. The warming will be more serious in the other two emission scenarios, especially in summer, for which an increase of about $2.5^{\circ} \mathrm{C}$ is projected in RCP 4.5 and $3{ }^{\circ} \mathrm{C}$ in RCP 8.5.

In the last thirty-year scenario (Figure 5), climate changes are projected to be compatible with a warming of $1.5^{\circ} \mathrm{C}$, assuming the RCP 2.6 mitigation pathway (first row of Figure 5), whereas the temperature increase may reach $3^{\circ} \mathrm{C}$ for the emission scenario $\mathrm{RCP}$ 4.5 (second row), and be even more than $5{ }^{\circ} \mathrm{C}$ in RCP 8.5 (third row).

It is worth noting that the projected warming in winter over Alpine region will be $1.5-2{ }^{\circ} \mathrm{C}, 3{ }^{\circ} \mathrm{C}, \sim 5{ }^{\circ} \mathrm{C}$, respectively, in the short-, medium-, and long-term, without 
undertaking mitigation actions. Such a temperature increase may seriously affect the hydrological cycle and, therefore, the availability of water resources over the year.

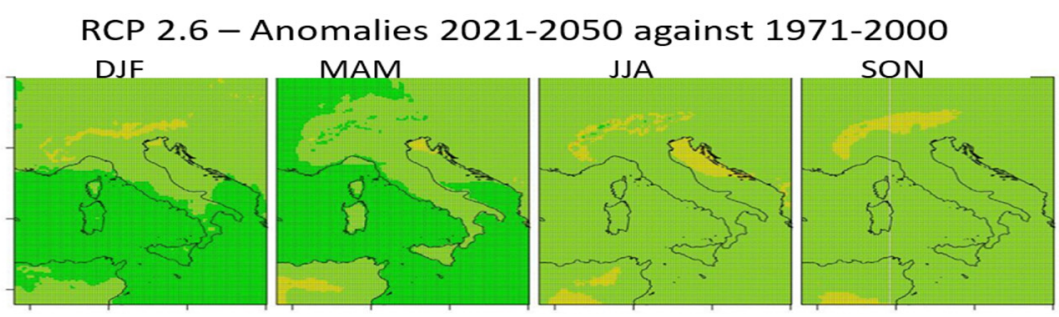

RCP 4.5 - Anomalies 2021-2050 against 1971-2000


RCP 8.5 - Anomalies 2021-2050 against 1971-2000



Figure 3. Seasonal Mean Surface temperature anomalies $\left({ }^{\circ} \mathrm{C}\right.$ ) expected by 2021-2050 (DJF, MAM, JJA, SON, respectively from first to fourth column), against the reference period 1971-2000 gathered by Euro-CORDEX ensemble models, under RCP 2.6 (top), RCP 4.5 (center), RCP 8.5 (bottom) configurations.

RCP 2.6 - Anomalies 2041-2070 against 1971-2000


RCP 4.5 - Anomalies 2041-2070 against 1971-2000
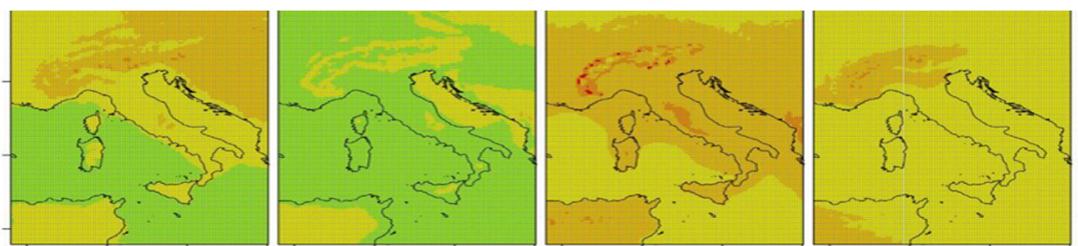

RCP 8.5 - Anomalies 2041-2070 against 1971-2000

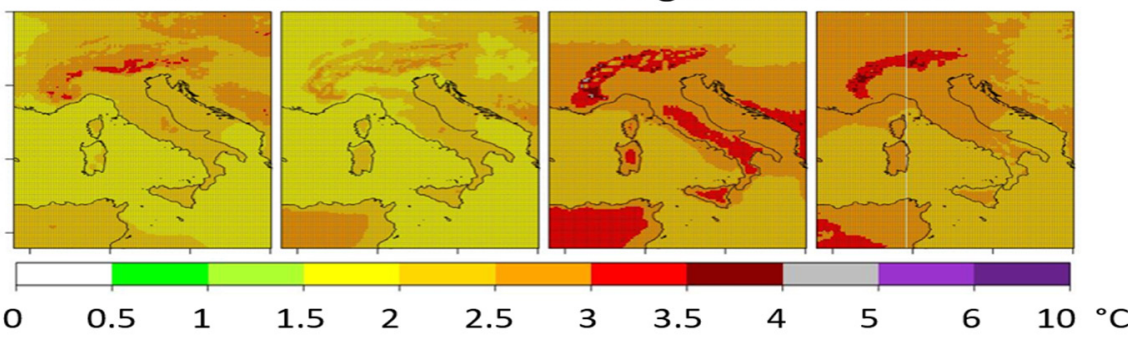

Figure 4. As Figure 3 but for anomalies expected by 2041-2070 against 1971-2000. 
RCP 2.6 - Anomalies 2071-2100 against 1971-2000

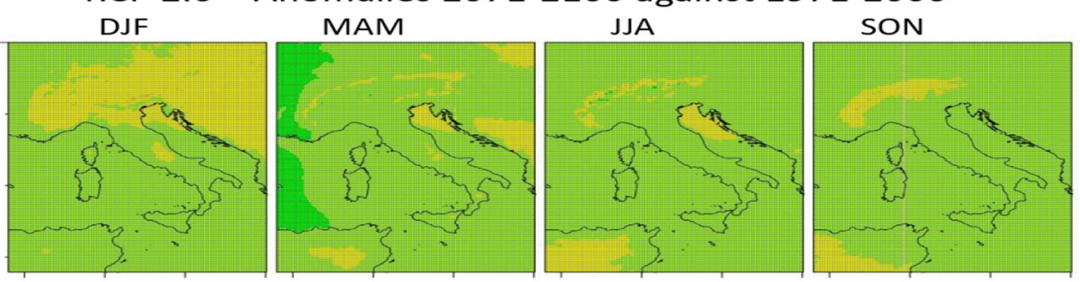

RCP 4.5 - Anomalies 2071-2100 against 1971-2000

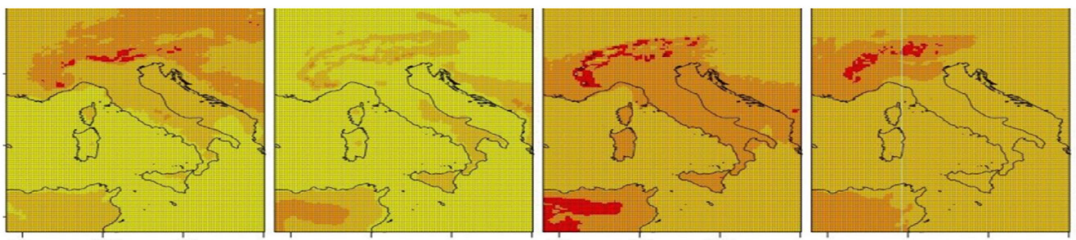

RCP 8.5 - Anomalies 2071-2100 against 1971-2000
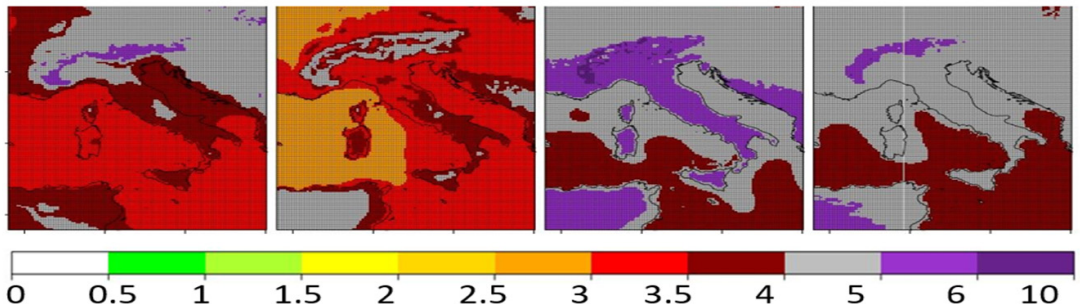

5



Figure 5. As Figure 3 but for anomalies expected by 2071-2100 against 1971-2000.

The following three figures illustrate the MMM scenarios computed for precipitation anomalies (expressed in percentage values), expected in the short- (Figure 6), medium(Figure 7) and long-term (Figure 8).
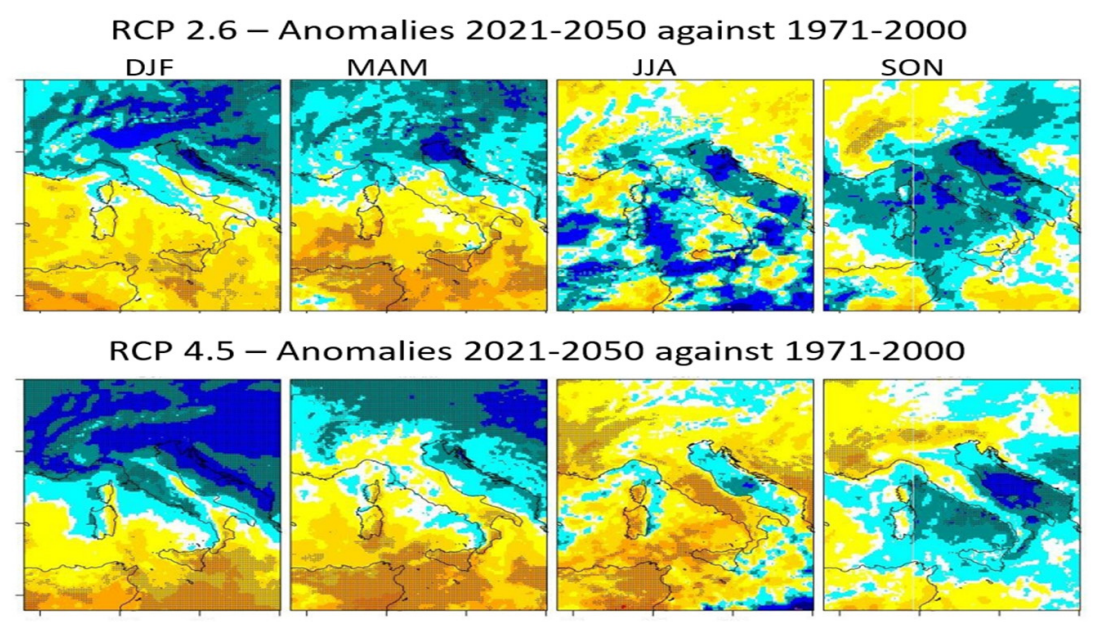

RCP 8.5 - Anomalies 2021-2050 against 1971-2000

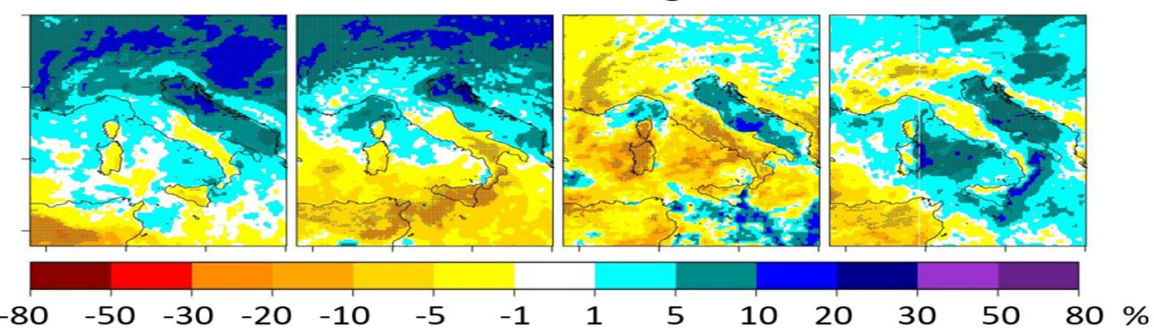

Figure 6. Seasonal Total precipitation anomalies (\%) expected by 2021-2050 (DJF, MAM, JJA, SON, respectively, from first to fourth column), against the reference period 1971-2000, gathered by EuroCORDEX ensemble models, under RCP 2.6 (top), RCP 4.5 (center), RCP 8.5 (bottom) configurations. 
RCP 2.6 - Anomalies 2041-2070 against 1971-2000

DJF

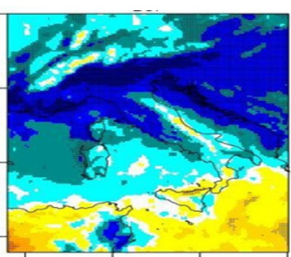

MAM

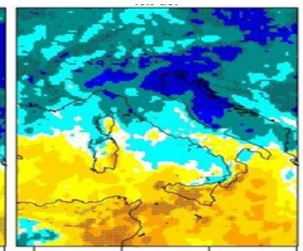

JJA

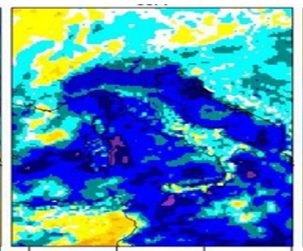

SON


$971-2000$

RCP 8.5 - Anomalies 2041-2070 against 1971-2000
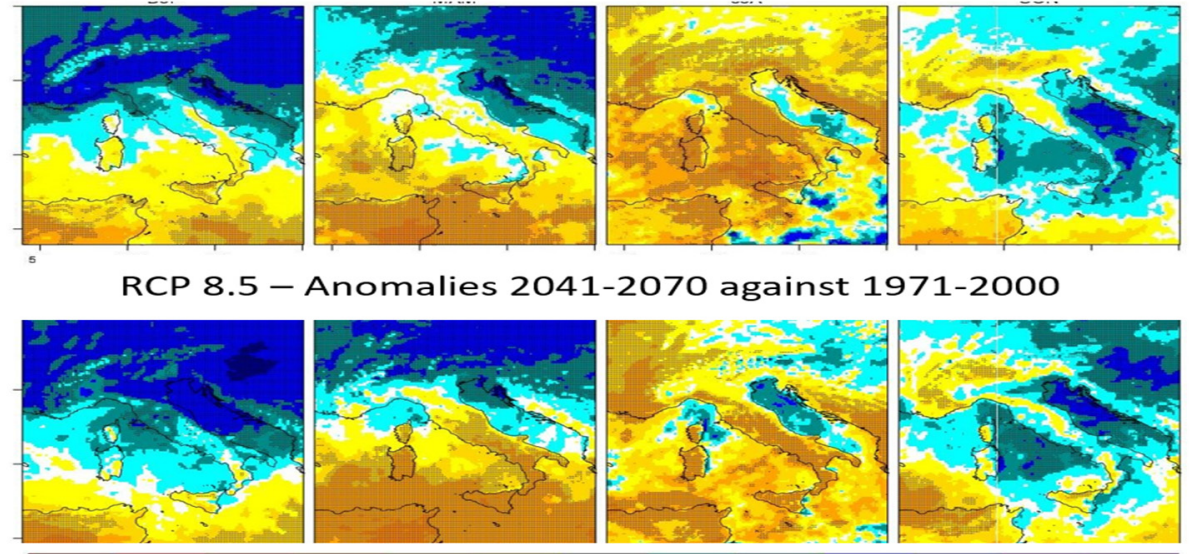

.



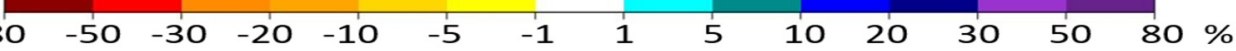

Figure 7. As Figure 6, but for anomalies expected by 2041-2070 against 1971-2000.

RCP 2.6 - Anomalies 2071-2100 against 1971-2000

DJF

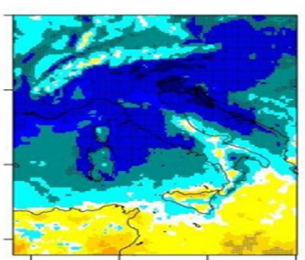

RCP $4.5-A n$
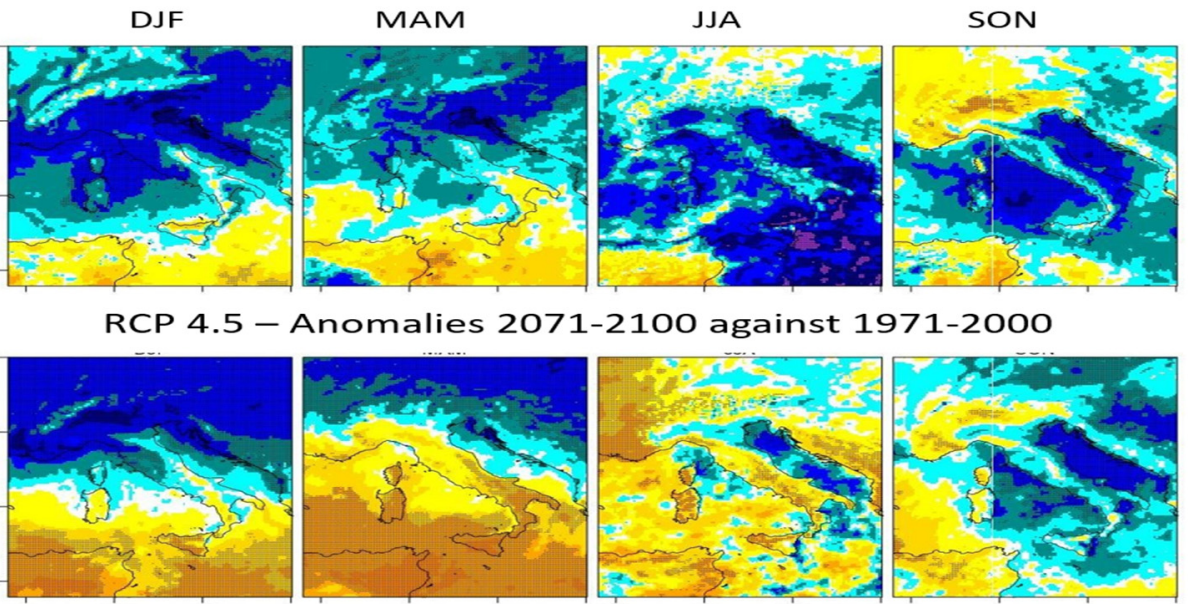

-2100 against 1971-2000

RCP 8.5 - Anomalies 2071-2100 against 1971-2000


Figure 8. As Figure 6, but for anomalies expected by 2071-2100 against 1971-2000.

As was observed in previous studies [39-41], precipitation changes are much more spatially heterogeneous compared with temperature changes, i.e., there are some areas in which a model projects an increase in precipitations, while another model highlights 
a decrease of them. Therefore, confidence in the precipitation change is lower than confidence in the temperature change. This is due, in large part, to the fact that temperature changes directly depend on radiative forcing, whereas precipitation variations are affected by a number of complex interactions, including changes in the water-holding capacity of a warming atmosphere, atmospheric circulation, evaporation, and other factors (e.g., [42]). High-resolution RCM experiments show that local forcing associated with complex topography and coastlines can substantially modulate large-scale signals, often to the point of being of the opposite sign. This spread causes some uncertainty in the multi-model scenarios, an uncertainty has to be taken into account in the assessment of the final results.

In the coming decades (Figure 6), a significant precipitation reduction is expected in summer and spring (in this case, only Southern Italy is affected) with values ranging between 5 and $10 \%$ depending on the emission scenario. In the other seasons, no significant signals are evident.

In the middle of the century (Figure 7), precipitations will likely decrease even more in summer and spring (in this case, only in Southern Italy) ranging between 10 and $20 \%$ in RCP 4.5 and RCP 8.5 .

At the end of the century (Figure 8), a significant precipitation reduction is expected in spring and summer over most of Italy under the configurations RCP 4.5 (up to $30 \%$ ) and RCP 8.5 (up to $50 \%$ ).

\subsection{Changes of Extreme Events}

The model performances in reconstructing climate extremes in the base-line climate period (1971-2000) are checked first. Then, the results regarding future MMM scenarios are discussed.

Drought conditions were characterized by the WMO ETCCDI index CDD (Consecutive Dry Days), calculated by considering the maximum length of a dry spell $(p r<1 \mathrm{~mm} / \mathrm{d})$.

The multi-model reconstruction underestimates the CDD index of a few days in spring and in autumn, and of about 10 days in summer in comparison with E-OBS data (Figure 9). However multi-model performances may be considered satisfactory in reconstructing the pattern of seasonal CDD fields for the reference period, pointing towards more frequent events in summer in Southern Italy.

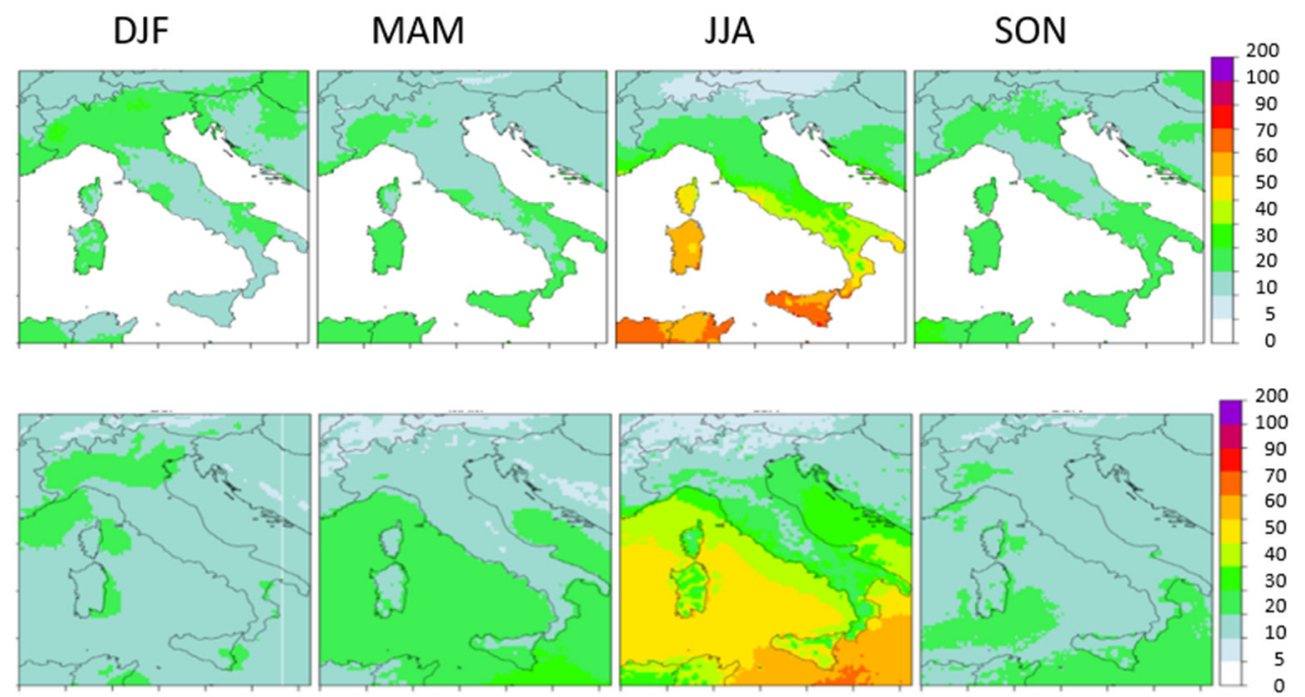

Figure 9. CDD reference scenarios 1971-2000 calculated at seasonal scale, expressed as maximum length (number of days) of dry spell ( $p r<1 \mathrm{~mm}$ ), estimated using E-OBS (top) and multi-model ensemble (bottom).

The following three figures (Figures 10-12) illustrate the CDD anomalies expected, respectively, in the short-, medium-, and long-term. 




RCP 4.5 - Anomalies 2021-2050 against 1971-2000



RCP 8.5 - Anomalies 2021-2050 against 1971-2000

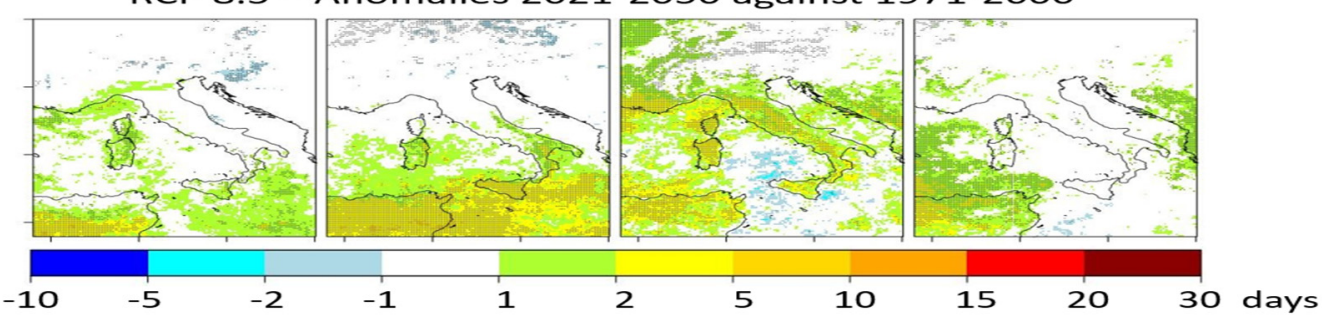

Figure 10. Seasonal CDD anomalies (unit = number of days), expressed as difference between the number of events projected in the future period 2021-2050 (DJF, MAM, JJA, SON, respectively, from first to fourth column) and the events computed in the reference period 1971-2000 under RCP 2.6 (top), RCP 4.5 (center), RCP 8.5 (bottom) configurations.

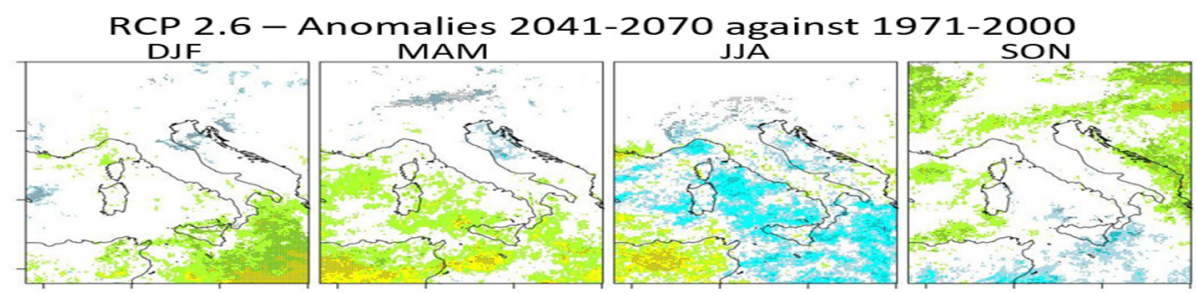

RCP 4.5 - Anomalies 2041-2070 against 1971-2000

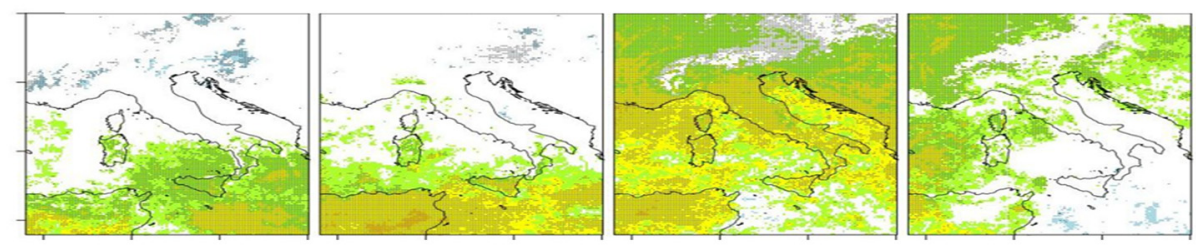

RCP 8.5 - Anomalies 2041-2070 against 1971-2000

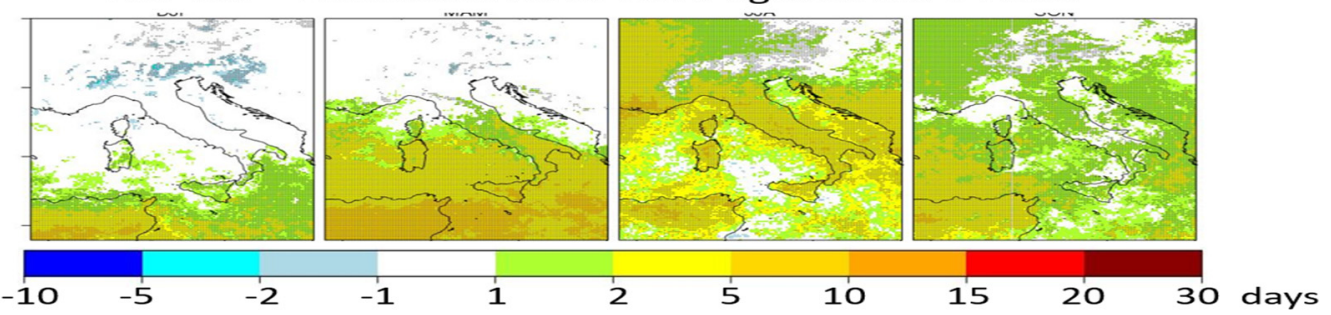

Figure 11. As Figure 10, but for the future scenario 2041-2070. 


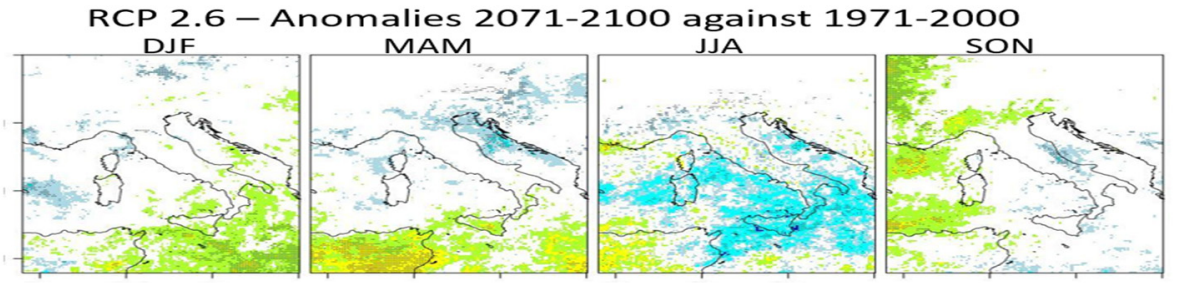

RCP 4.5 - Anomalies 2071-2100 against 1971-2000

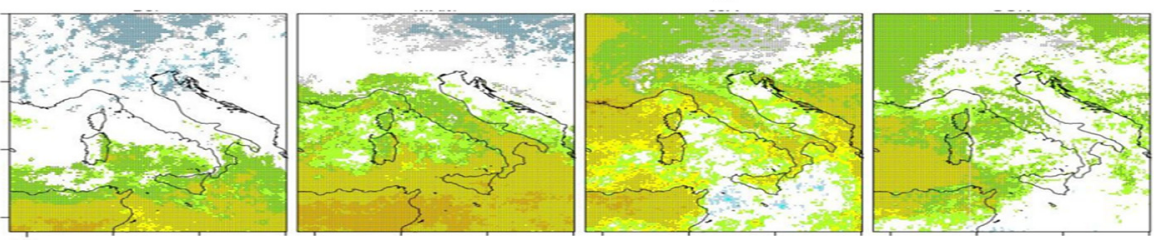

RCP 8.5 - Anomalies 2071-2100 against 1971-2000

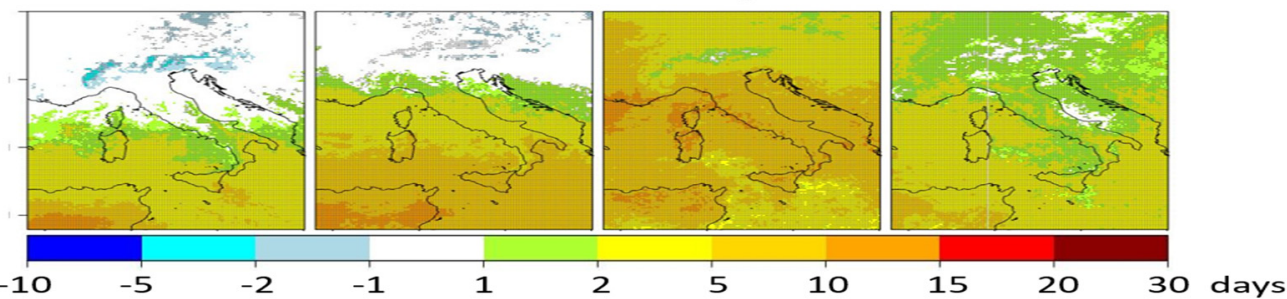

Figure 12. As Figure 10, but for the future scenario 2071-2100.

In general, no signal highlights changes in drought conditions under the RCP 2.6 configuration. Instead, the maximum length of dry spell is expected to grow significantly, above all in summer in Southern Italy in the RCP 4.5 and RCP 8.5 hypothesis. The stippled region highlights a significant increase in $\mathrm{CDD}$, ranging from 2 to 10 days, over much of Italy during the summer.

Under RCP 4.5 and RCP 8.5 configurations, a lengthening of CDD is expected in spring and autumn, with values ranging from 2 (RCP 4.5) to 5 (RCP 8.5) days after the middle of the century. This may be particularly worrying in spring because increasing drought conditions may seriously impact the agricultural sector.

Changes in extreme precipitations were assessed by computing the WMO ETCCDI index R99PTOT (precipitation due to extremely wet days, when $p r>$ 99th percentile of the reference period).

For this purpose, first, the 99th percentile (RR99) fields have been computed at seasonal scale by using both E-OBS and MMM data. Figure 13 allows for comparison between the corresponding seasonal RR99 patterns. It is worth noting that the MMM seasonal reconstructions are wetter than the corresponding E-OBS scenarios over Southern Italy, with overestimations that reach up to $100 \%$. However, the multi-model pattern is able to satisfactorily describe the main characteristics of the precipitation regime by identifying the northern regions as the wettest in Italy, as well as the season cycle, with summer as the driest season and autumn as the wettest.

As for the other indices, the anomalies were estimated by computing the differences between the future and reference R99PTOT values in the short-, medium-, and long-term (Figures 14-16, respectively). 

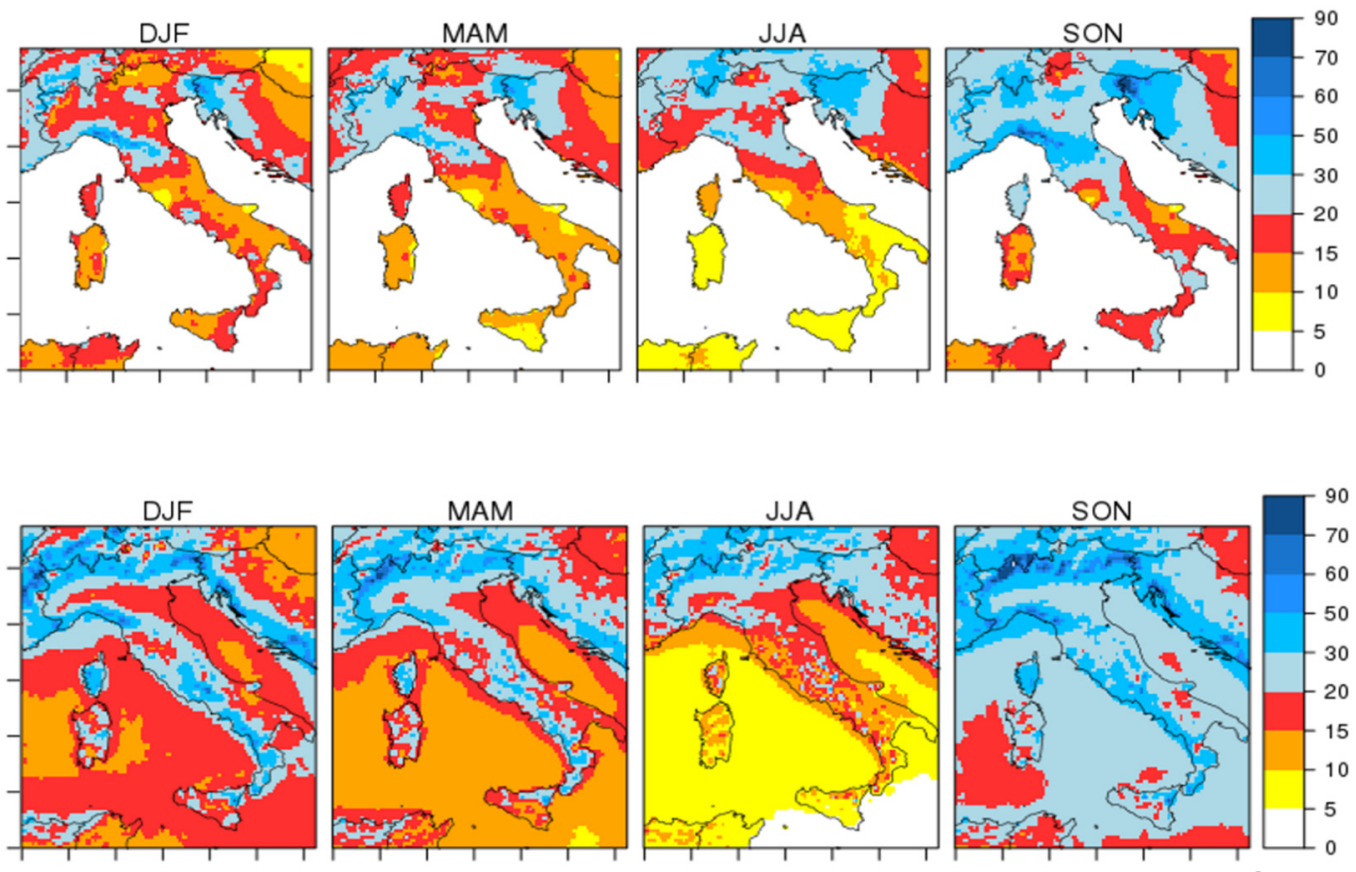

Figure 13. RR99 reference scenarios (expressed in mm/d) calculated at seasonal scale (DJF, MAM, JJA, SON), estimated using the base: E-OBS (top) and multi-model ensemble (bottom).



RCP 4.5 - Anomalies 2021-2050 against 1971-2000



RCP 8.5 - Anomalies 2021-2050 against 1971-2000



Figure 14. Seasonal R99PTOT anomalies (unit = number of days), expressed as difference between the number of events (number of days) projected in the future period 2021-2050 (DJF, MAM, JJA, SON, respectively, from first to fourth column) and those in the reference period 1971-2000 under RCP 2.6 (top), RCP 4.5 (center), RCP 8.5 (bottom) configurations. 


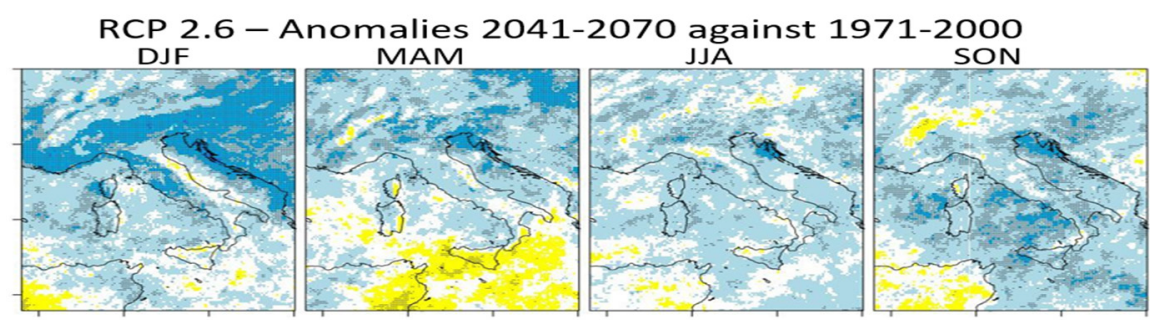

RCP 4.5 - Anomalies 2041-2070 against 1971-2000

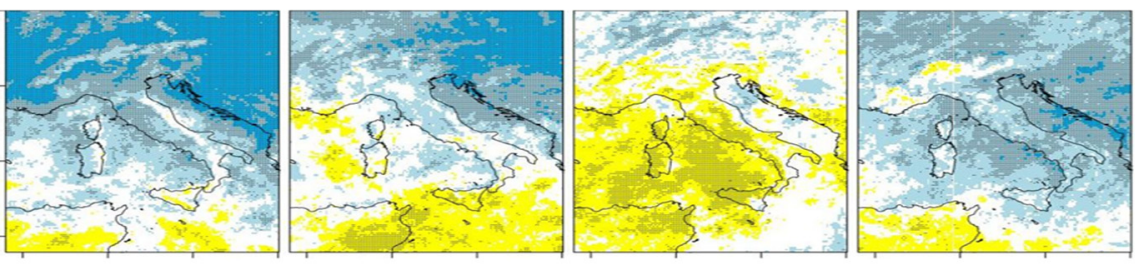

RCP 8.5 - Anomalies 2041-2070 against 1971-2000

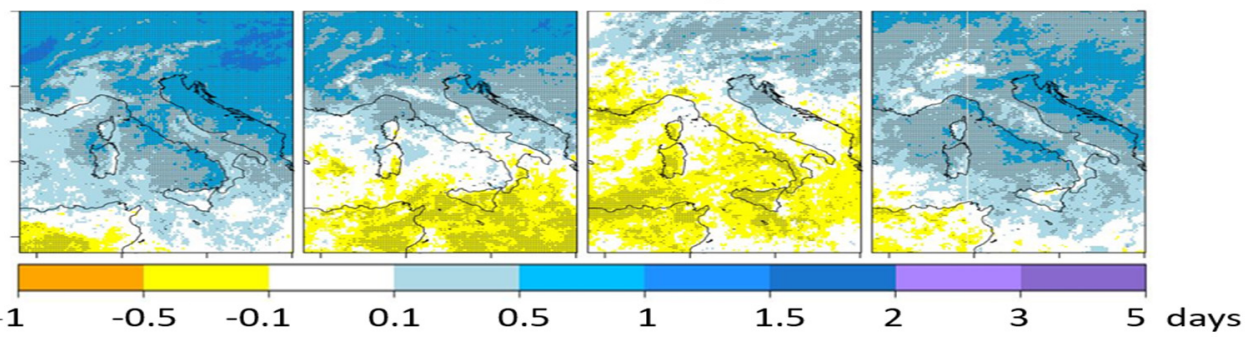

Figure 15. As Figure 14, but for the future scenario 2041-2070.

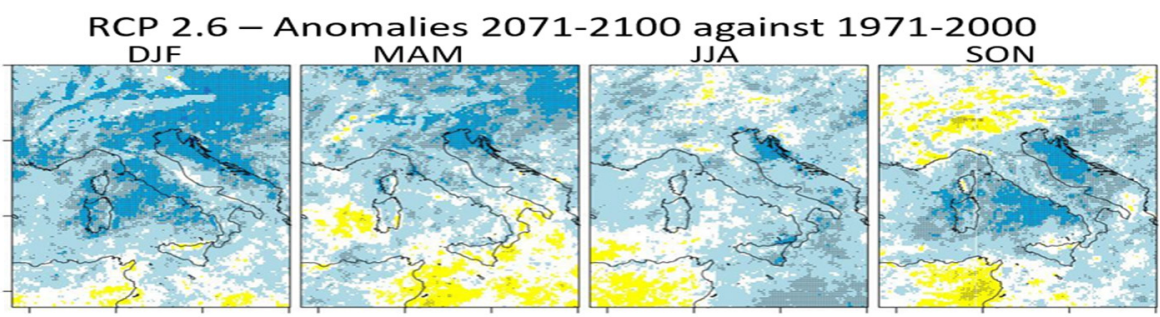

RCP 4.5 - Anomalies 2071-2100 against 1971-2000
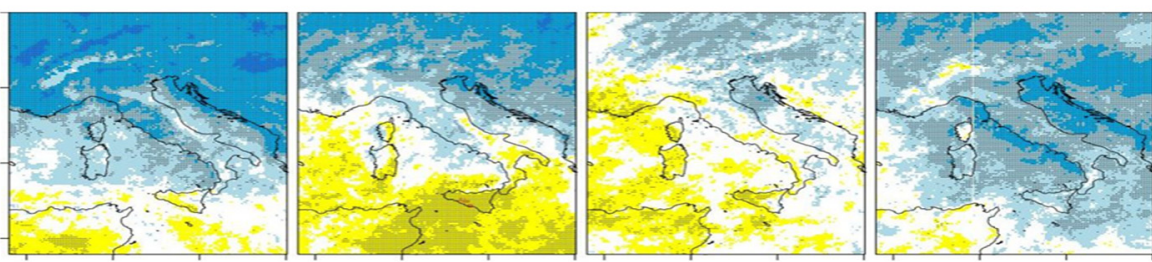

RCP 8.5 - Anomalies 2071-2100 against 1971-2000

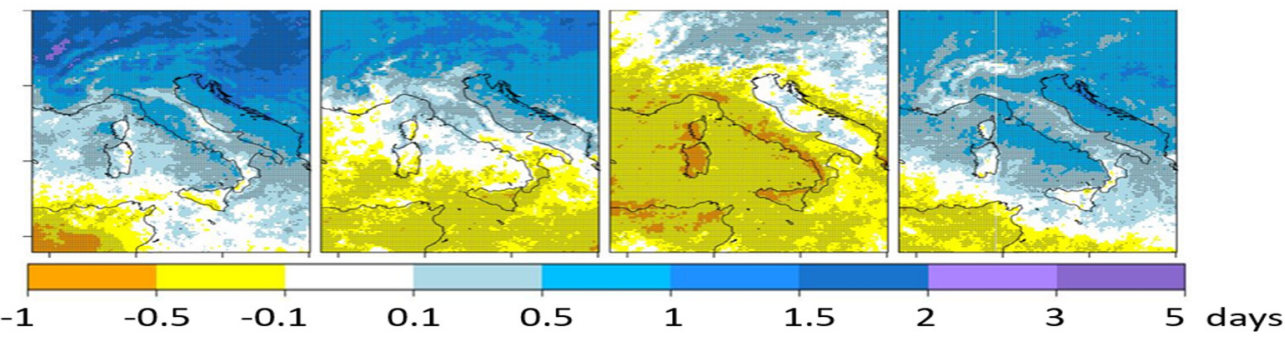

Figure 16. As Figure 14, but for the future scenario 2071-2100.

In general, no significant change is expected under RCP 2.6 configuration. Instead, extreme precipitations are likely to increase, with different intensities depending on both region and season in RCP 4.5 and RCP 8.5 hypotheses. There is some uncertainty in localizing the most affected regions in the future, but a clear trend toward exacerbation of 
the weather conditions is evident during the century, locally, over northern regions and the Tyrrhenian coasts.

\section{Discussion and Conclusions}

The availability of climate data has never been greater. However, availability of climate data does not automatically translate into usability, as the uncertainty of regional climate changes projections is still large and has to be accounted for, especially in impact and adaptation studies.

There is great concern regarding the effects of climate change on human societies and natural ecosystems. As the response of the Earth's hydrologic cycle to global warming is of the greatest interest, this study aimed to characterize the precipitation regime over Italy on the basis of 11 high-resolution Euro-CORDEX models by highlighting some local trends in the different Italian regions the have been less considered to date.

A range of future scenarios was elaborated by considering average temperature and total precipitation changes. Moreover, an analysis of changes in the rainfall regime was carried out by using the two climate extreme indices, CDD and R99PTOT, to describe drought conditions and extreme precipitation, respectively. Such scenarios were inferred under three Representative Concentration Pathways (RCP 8.5, RCP 4.5, and RCP 2.6) to investigate how socioeconomic factors may affect climate change in the future.

The signals inferred from the Euro-CORDEX simulations confirm and strengthen the obtained results by analyzing the ENSEMBLES and Med-CORDEX models in previous studies $[39,41,43,44]$ and, thanks to the high-resolution models, updated knowledge about climate change in Italy was achieved from the greater orographic details.

Confidence in climate change projections varies by region and by climate variable.

The most important result is that a warming is projected, with a marked seasonality and an intensity depending on the orography (high-altitude areas are the most vulnerable) and, especially, the greenhouse gas emission scenarios. In fact, in the near-term (to approximately 2040), projected warming will be similar under all emission pathways. However, by the late 21st century, the differences between possible emission pathways will have a considerable effect: the estimates indicate that the temperatures are likely to increase from an additional $1{ }^{\circ} \mathrm{C}$ (for a low-emission scenario, RCP 2.6) to about $4-5^{\circ} \mathrm{C}$ (for a high-emission scenario, RCP 8.5) respect to the base-line period (1971-2000).

Although precipitation increases globally $[6,9]$, relatively complex patterns of change have been discovered at the local level, with areas of increasing and decreasing precipitation. These variations are a result of climate processes and feedbacks that depend on local conditions, as local forcings (e.g., topography, land use), and energy and water fluxes affect convective activity. The projections point towards an increase in total precipitation in winter over North Italy from $5 \%$ to $30 \%$ over the century, and a likely decrease in summer of about $5-10 \%$ up to $50 \%$, respectively, in the short-, medium- and long-term in RCP 8.5 and RCP 4.5 .

Changes in climate extremes are a consequence of changes in both temperature and precipitation: in case of partial or no mitigation, coastal areas will be affected by an increase in extreme precipitation with values depending on region and season. In particular, coastlines will be affected by an increase of one or two more extreme precipitation events during the winter and autumn. However, no significant signals were seen if drastic green-house gas reduction is undertaken (RCP 2.6). Regarding drought conditions, no signal highlights significant changes under RCP 2.6 configuration. Instead, in RCP 4.5 and RCP 8.5, the maximum length of dry spell is expected to grow until 10-15 days during the summer in Southern Italy, indicating an increasing risk of droughts.

In general, climate extremes will be much less critical if mitigation actions are undertaken. However, it is worth noting that some climate impacts can no longer be avoided, even in the case of low anthropogenic radiative forcing. 
Author Contributions: Conceptualization, methodology, software, validation, formal analysis, investigation, writing - review visualization Paola Faggian.The author has read and agreed to the published version of the manuscript.

Funding: This work has been financed by the Research Fund for the Italian Electrical System under the Contract Agreement between RSE S.p.A. and the Ministry of Economic Development -General Directorate for the Electricity Market, Renewable Energy and Energy Efficiency, Nuclear Energy in compliance with the Decree of 16 April 2018.

Data Availability Statement: We acknowledge the World Climate Research Programme's Working Group on Regional Climate, and the Working Group on Coupled Modelling, former coordinating body of CORDEX and responsible panel for CMIP5.

Acknowledgments: We acknowledge the E-OBS dataset from the EU-FP6 project UERRA (http: / / www.uerra.eu) and the Copernicus Climate Change Service, and the data providers in the ECA\&D project (https: / www.ecad.eu). The author is very grateful to Goffredo Decimi (Researcher at RSE) for his help in downloading the model simulations and for preprocessing data. She would also like to thank two anonymous reviewers for their helpful comments.

Conflicts of Interest: The author declares no conflict of interest.

\section{References}

1. Munich Re, Geo Risks Research, Climate Change and Natural Disasters, NatCatSERVICE. Available online: https://www. munichre.com/topics-online/en/climate-change-and-natural-disasters.html (accessed on 1 March 2019).

2. United Nations. Take Action for the Sustainable Development Goals. Available online: https://www.un.org/sustainabledevelopment/ sustainable-development-goals / (accessed on 1 March 2019).

3. United Nations. Sustainable Development Goals. Goal 13: Take Urgent action to Combat Climate Change and Its Impacts. Climate Action. Available online: https:/ / www.un.org/sustainabledevelopment/climate-change/ (accessed on 5 March 2019).

4. European Environment Agency. Water Resources in Europe in the Context of Vulnerability. EEA 2012 State of Water Assessment; Report No 11/2012; EEA: Copenhagen, Denmark, 2012.

5. Intergovernmental Panel on Climate Change (IPCC). Climate Change 2007. The Physical Science Basis. Working Group I Contribution to the Fourth Assessment Report of the Intergovernmental Panel on Climate Change; Solomon, S., Qin, D., Manning, M., Marquis, M., Averyt, K., Tignor, M.M.B., Miller, H.L., Jr., Chen, Z., Eds.; Cambridge University Press: Cambridge, UK, 2007 ; pp. 1-996.

6. Intergovernmental Panel on Climate Change (IPCC). Climate Change 2013. The Physical Science Basis. Contribution of Working Group I to the Fifth Assessment Report of the Intergovernmental Panel on Climate Change; Stocker, T.F., Dahe, Q., Plattner, G.-K., Tignor, M.M.B., Allen, S.K., Boschung, J., Nauels, A., Xia, Y., Bex, V., Midgley, P.M., Eds.; Cambridge University Press: Cambridge, UK; New York, NY, USA, 2013; pp. 1-1029.

7. Fischer, E.M.; Knutti, R. Observed heavy precipitation increase confirms theory and early models. Nat. Clim. Chang. 2016, 6, 986-990. [CrossRef]

8. Lenderink, G. Exploring metrics of extreme daily precipitation in a large ensemble of regional climate model simulations. Clim. Res. 2010, 44, 151-166. [CrossRef]

9. Giorgi, F.; Raffaele, F.; Coppola, E. The response of precipitation characteristics to global warming from climate projections. Earth Syst. Dynam. 2019, 10, 73-89. [CrossRef]

10. IPCC. 2018: Global Warming of $1.5^{\circ} \mathrm{C}$. An. IPCC Special Report on the Impacts of Global Warming of $1.5^{\circ} \mathrm{C}$ above Pre-Industrial Levels and Related Global Greenhouse Gas. Emission Pathways, in the Context of Strengthening the Global Response to the Threat of Climate Change, Sustainable Development, and Efforts to Eradicate Poverty; Masson-Delmotte, V., Zhai, P., Pörtner, H.O., Roberts, D., Skea, J., Shukla, P.R., Pirani, A., Moufouma-Okia, W., Péan, C., Pidcock, R., et al., Eds.; 2018. Available online: http://www.ipcc.ch/report/sr15/ (accessed on 5 January 2020).

11. ESOTC 2018. Headline Climate Indicators. Surface Temperature. Available online: https://climate.copernicus.eu/surfacetemperature (accessed on 5 January 2020).

12. Forzieri, G.; Feyen, L.; Russ, S.; Vousdoukas, M.; Alfuieri, L.; Outten, S.; Migliavacca, M.; Bianchi, A.; Rojas, R.; Cid, A. Multi-hazard assessment in Europe under climate change. Clim. Chang. 2016, 37, 105-119. [CrossRef]

13. U.S. Department of Energy. U.S. Energy Sector Vulnerabilities to Climate Change and Extreme Weather. DOE/PI-0013, 2013. Available online: https:/ /apps.dtic.mil/sti/pdfs/ADA583709.pdf(accessed on 5 January 2020).

14. Sturchio, A.; Fioriti, G.; Salusest, V.; Calcara, L.; Pompili, M. Thermal behavior of distribution MV underground cables. In Proceedings of the 2015 AEIT International Annual Conference (AEIT), Naples, Italy, 14-16 October 2015.

15. Bonanno, R.; Lacavalla, M. A feasibility analysis aimed at defining an alert system for Distribution MV Underground Cables. In Proceedings of the 2020 AEIT International Annual Conference, Catania, Italy, 23-25 September 2020.

16. Faggian, P.; Decimi, G. Exacerbation of heat waves and droughts over Italy in the next decades under different socio-economic pathways. In Proceedings of the 2020 AEIT International Annual Conference, Catania, Italy, 23-25 September 2020. 
17. Faggian, P.; Decimi, G. An updated investigation about climate-change hazards that might impact electric infrastructures. In Proceedings of the 2019 AEIT International Annual Conference, Florence, Italy, 18-20 September 2019.

18. Faggian, P.; Bonanno, R. Raising awareness on climate-change related hazards that might impact electric infrastructure. In Proceedings of the 2018 AEIT International Annual Conference, Bari, Italy, 3-5 October 2018.

19. Italy's National Energy Strategy. Ministro dello Sviluppo Economico, Ministro dell'Ambiente e della Tutela del Territorio e del Mare. 2017. Available online: https://www.mise.gov.it/images/stories/documenti/BROCHURE_ENG_SEN.PDF (accessed on 6 January 2020).

20. Ministry of the Economic Developement. Energy and Climate 2030. Available online: https://www.mise.gov.it/index.php/it/ energia/energia-e-clima-2030 (accessed on 8 January 2020).

21. Flato, G.; Marotzke, J.; Abiodun, B.; Braconnot, P.; Chou, S.C.; Collins, W.; Cox, P.; Driouech, F.; Emori, S.; Eyring, V.; et al. Evaluation of climate models. In Climate Change 2013: The Physical Science Basis (Contribution of Working Group I to the Fifth Assessment Report of the Intergovernmental Panel on Climate Change); Stocker, T.F., Qin, D., Plattner, G.-K., Tignor, M., Allen, S.K., Boschung, J., Nauels, A., Xia, Y., Bex, V., Midgley, P.M., Eds.; Cambridge University Press: Cambridge, UK; New York, NY, USA, 2013; pp. 741-866.

22. Giorgi, F.; Gutowski, W. Regional dynamical downscaling and the CORDEX initiative. Annu. Rev. Environ. Resour. 2015, 40, 467-490. [CrossRef]

23. Gutowski, W.; Giorgi, F.; Timbal, B.; Frigon, A.; Jacob, D.; Kang, H.; Raghavan, K.; Lee, B.; Lennard, C.; Nikulin, G.; et al. WCRP Coordinated Regional Downscaling EXperiment (CORDEX): A diagnostic MIP for CMIP6. Geosci. Model. 2016, 9, 4087-4095. [CrossRef]

24. Sordo-Ward, A.; Granados, A.; Glesias, A.; Garrote, L.; Bejarano, M.D. Adaptation Effort and Performance of Water Management Strategies to Face Climate Change Impacts in Six Representative Basins of Southern Europe. Water 2019, 11, 1078. [CrossRef]

25. Christensen, J.H.; Larsen, M.A.D.; Christensen, O.B.; Drews, M.; Stendel, M. Robustness of European climate projections from dynamical downscaling. Clim. Dyn. 2019, 53, 4857-4869. [CrossRef]

26. European Environment Agency. Water Resources: Quantity and Flows-SOER 2010 Thematic Assessment, State of the Environment; Report No 1/2010; EEA: Copenhagen, Denmark, 2010.

27. Brunetti, M.; Maugeri, M.; Monti, F.; Nanni, T. Changes in daily precipitation frequency and distribution in Italy over the last 120 years. J. Geophys. Res. 2004, 109, D05102. [CrossRef]

28. Bucchignani, E.; Montesarchio, M.; Zollo, A.L.; Mercogliano, P. High-resolution climate simulations with COSMO-CLM over Italy: Performance evaluation and climate projections for the 21st century. Int. J. Cliamatol. 2016, 36, 735-756. [CrossRef]

29. Jacob, D.; Petersen, J.; Eggert, B.; Alias, A.; Christensen, O.B.; Bouwer, L.M.; Braun, A.; Colette, A.; Déqué, M.; Georgievski, G.; et al. EURO-CORDEX: New high-resolution climate change projections for European impact research. Reg. Environ. Chang. 2014, 14, 563-578. [CrossRef]

30. WMO. Guidelines on Analysis of Extremes in a Changing Climate in Support. of Informed Decisions for Adaptation; Technical Report WCDMP. No. 72, WMO/TD-No. 1500; WHO: Geneva, Switzerland, 2009.

31. Coordinated Downscaling Experiment-European Domain. Available online: http://www.euro-cordex.net/ (accessed on 2 January 2018).

32. Van Vuuren, D.P.; Edmonds, J.; Kainuma, M.; Riahi, K.; Thomson, A.; Hibbard, K.; Hurtt, G.C.; Kram, T.; Krey, V.; Lamarque, J.-F.; et al. The representative concentration pathways: An overview. Clim. Chang. 2011, 109, 5-31. [CrossRef]

33. Hofstra, N.; Haylock, M.; New, M.; Jones, P.D. Testing E-OBS European High-Resolution Gridded Data Set of Daily Precipitation and Surface Temperature. J. Geophys. Res. 2009, 114, D21101. [CrossRef]

34. European Climate Assessment and Dataset. Available online: http:/ / eca.knmi.nl/dailydata (accessed on 4 January 2018).

35. Meehl, G.A. Overview of the Copupled Model Intercomparison Project. Bull. Am. Meteorol. Soc. 2005, 86, 89-93.

36. Collins, M.M.; Knutti, R.; Arblaster, J.; Dufresne, J.L.; Fichefet, T.; Friedlingstein, P.; Gao, X.; Gutowski, W.J.; Johns, T.; Krinner, G.; et al. Long-term climate change: Projections, commitments and irreversibility. In Climate Change. 2013: The Physical Science Basis (Contribution of Working Group I to the Fifth Assessment Report of the Intergovernmental Panel on Climate Change); Stocker, T.F., Qin, D., Plattner, G.-K., Tignor, M., Allen, S.K., Boschung, J., Nauels, A., Xia, Y., Bex, V., Midgley, P.M., Eds.; Cambridge University Press: Cambridge, UK; New York, NY, USA, 2013; pp. 1029-1136.

37. Faggian, F.; Bonanno, R.; Lacavalla, M.; Marcacci, P.; Pirovano, G. Research and operational activities to cope with wet snow impacts on overhead power lines in current and future climate over Italy. In Proceedings of the CIGRE'-SEERC 2nd South East European Regional CIGRE Conference, Kyiv, Ukraine, 12-13 June 2018.

38. Landelius, T.; Dahlgren, P.; Gollvik, S.; Jansson, A.; Olsson, E. A high-resolution regional reanalysis for Europe. Part 2: 2D analysis of surface temperature, precipitation and wind. Q. J. R. Meteorol. Soc. 2016, 142, 2132-2142. [CrossRef]

39. Faggian, P. Climate Change projections for Mediterranean Region with focus over Alpine. J. Environ. Sci. Eng. 2015, 4, 482-500. [CrossRef]

40. Giorgi, F.; Lionello, P. Climate change projections for the Mediterranean region. Glob. Planet. Chang. 2008, 63, 90-104. [CrossRef]

41. Faggian, P. Estimating fire danger over Italy in the next decades. Euro-Mediterr. J. Environ. Integr. 2018, 3, 1-13. [CrossRef]

42. Shepherd, T.G. Atmospheric circulation as a source of uncertainty in climate change projections. Nat. Geosci. 2014, 7, 703-708. [CrossRef] 
43. Bonanno, R.; Faggian, P. Changes in the precipitation regime over the Italian Peninsula and their possible impacts on the electric system. Tethys J. Mediterr. Meteorol. Climatol. 2018, 15, 18-30. [CrossRef]

44. Faggian, P.; Giorgi, F. An analysis of global model projections over Italy, with particular attention to the Italian Greater Alpine Region (GAR). Clim. Chang. 2009, 96, 239-258. [CrossRef] 